\title{
Engaged Scholarship: (Re) Focusing on Our Mission
}

\author{
Lisa Kirtman, Erica Bowers and John L. Hoffman
}

\begin{abstract}
Although the mission statements of most comprehensive teaching institutions of higher education include serving as a resource for the global and local community, the tenure and promotion process typically does not recognize these community partnerships as research endeavors, even when the nature of the work is firmly grounded in sound empirical practice. This paper shares the process a faculty task force undertook to gain consensus and incorporate language on engaged scholarship within the College's personnel document. The process took four years and included five steps: (a) establish a definition of engaged scholarship grounded in scholarly literature, (b) gather practice-oriented information regarding best practices as well as faculty perceptions of engaged scholarship practice, (c) create policy language for department personnel documents, (d) generate consensus among faculty for the policy language, and (g) submit final documents to the University Personnel committee for approval. The paper concludes with a discussion of implications for policy and practice.
\end{abstract}

\section{Introduction}

Perhaps at no prior time has it been more important for college and university faculty to partner with schools, communities, and other stakeholders in shared efforts to improve the quality of education throughout the educational pipeline from birth through college and beyond. For example, consider the high school dropout rate in the state of California - the context for this paper. Nearly one in five (19.2\%) of the high school students who began in the 2009-2010 school year did not graduate in 2013. The corresponding dropout rate was considerably higher for populations such as Latinos (23.6\%) and African Americans (31.9\%), students from low-income families (24.6\%), students from the families of migrant workers (24.2\%), and students in special education (37.8\%) (California Dropout Research Project, 2015). In order to address these concerns, a variety of educational scholars and practitioners have called for greater attention to educational partnerships (Leonard, 2011; Maurrasse, 2001; Person et al., 2014; Rodríguez \& Conchas, 2009) as well as data-informed decision-making (Campbell \& Levin, 2009; Mandinach, 2012; Moss, 2007).

Many California universities have missions that would seemingly address these issues. According to the mission statement of California State University Fullerton (CSUF), "We are a comprehensive, regional university with a global outlook... Our expertise and diversity serve as a distinctive resource and catalyst for partnerships with public and private organizations. We strive to be a center of activity essential to the intellectual, cultural, and economic development of our region." However, similar to most universities, the CSUF tenure and promotion structures at the beginning of this project did not reward community partnership work as a scholarly research endeavor, even when those practices reflected sound empirical practice. Instead, this type of work would have been classified as service. When studying tenure promotion practices, Green (2008) found that service carried equal weight with teaching and scholarship for just $16.2 \%$ of a sample of 154 graduate school deans. When discussing this finding in a historical context, Green noted, "the scholarship role has become even more salient in tenure and promotion decisions during the 21 st century and teaching and service roles have become less influential" (p. 125). Thus, whereas many college and university faculty members are potential valuable partners to schools that wish to make greater use of data to inform decision-making, the incentive structures for these faculty 
do not reward this work, even when that work aligns well with the mission of the institution and the needs of the community.

Beginning in 2010, the College of Education at CSUF began preliminary work on a strategic plan to refocus college efforts on its mission and the mission of the University. Among the outcomes of this process were strategic initiatives aimed at (a) strengthening partnerships with regional schools and community colleges, (b) promoting just, equitable, and inclusive education, (c) extending work related to educational technology, and (d) revising faculty roles and responsibilities to better tenure and promotion structures with the mission of the University and the College. A central component of the latter initiative was adding "engaged scholarship" to the tenure and promotion process. By adding engaged scholarship to the tenure and promotion process, faculty would be able to enact the mission through their work and be a distinctive resource to improve education for California's children.

In this paper, we will delineate the four-year process that culminated in 2015 with the adoption of engaged scholarship by the College as a whole, and its incorporation into each of the sets of department personnel standards within the College of Education at CSUF. The focus of this paper will be on how the engaged scholarship task force, which consisted of faculty representatives from each of the College's five departments (and the authors of this paper), generated consensus among more than 100 faculty members in defining engaged scholarship and recognizing it under the umbrella of scholarship within the tenure and promotion process. We will organize the paper around five steps or phases of the process, followed by a discussion of potential implications for policy and practice. Whereas the beginning of each step was sequential, there was significant overlap in the steps. The five steps are as follows (see also Figure 1 below): (a) establish a definition of engaged scholarship grounded in scholarly literature, (b) gather practice-oriented information regarding best practices as well as faculty perceptions of engaged scholarship practice, (c) create policy language for department personnel documents, (d) generate consensus among faculty for the policy language, and (g) submit final documents to the University Personnel committee for approval.

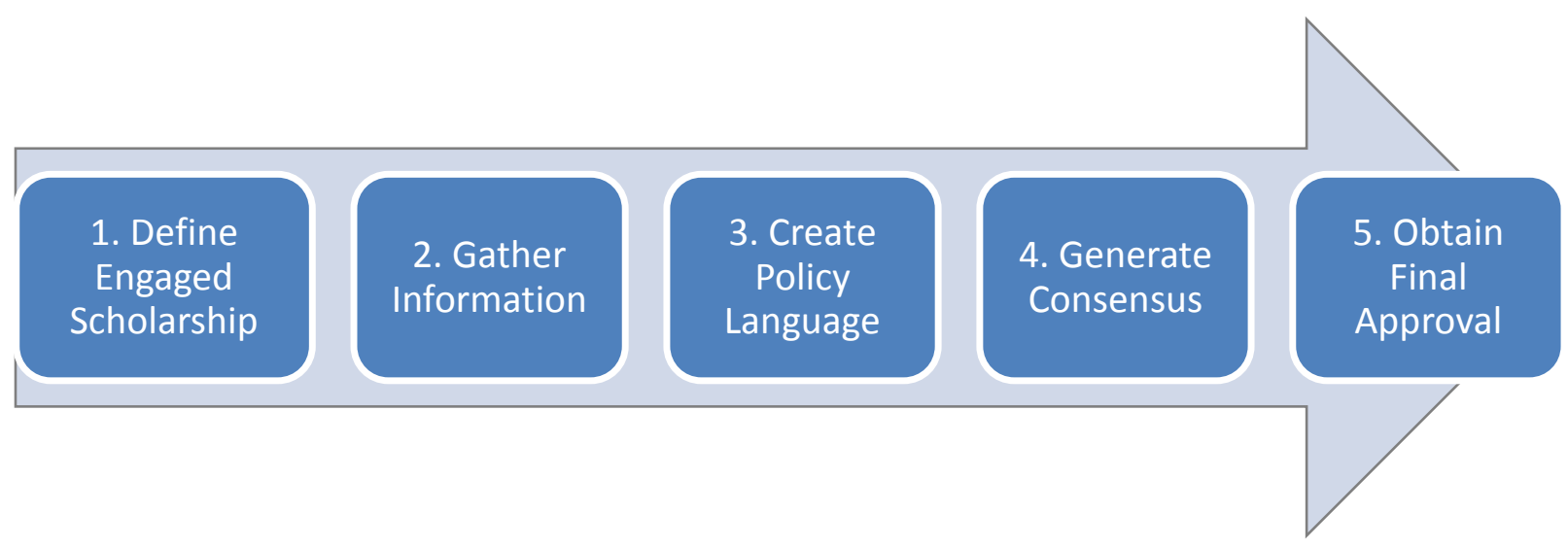

Figure 1. Steps taken to establish engaged scholarship

\section{Overview of the Task Force's Work}

In Fall 2011, the College of Education created the "Faculty Roles and Expectations Strategic Planning Task Force" (hereafter, Faculty Roles Committee or Committee). The Committee consisted of five faculty members, one from each of the College's five departments: (a) Elementary and Bilingual Education, (b) Secondary Education, (c) Special Education, (d) Literacy and Reading Education, and (e) Educational Leadership. At the time of formation, two of the five faculty were tenured full professors, one was a tenured associate, and two were non-tenured assistance professors. The Faculty Roles Committee was 
broadly charged with the task of aligning the college culture and expectations for all faculty, staff, and students to consistently reflect the college vision. More specifically, the committee was asked to develop guidelines to streamline the content of the portfolios submitted by probationary faculty during periods of review and to identify means of recognizing and rewarding engaged scholarship within the tenure and promotion process.

\section{Step One: Define Engaged Scholarship}

As a first step, the Faculty Roles Committee worked to either identify or generate a definition of engaged scholarship for the College. Given the broader context of the College's strategic plan, the Committee also aimed to connect engaged scholarship to the related initiatives of educational partnerships and of just, equitable, and inclusive education. This step served to be one of the most extensive for the entire process, but it also helped to ensure that the work was firmly grounded in scholarly literature. In the end, it also led to a stronger foundation for the definition of engaged scholarship.

Educational partnerships. The theory and practice of community engagement is not a new conversation. In 1996, Boyer proposed that universities broaden the definition of scholarship. He argued that "the academy must become a more vigorous partner in the search for answers to our most pressing, social, civic, economic and moral problems" (p. 19). Additionally, numerous studies (Leonard, 2011; Maurrasse, 2001; Person et al., 2014; Rodríguez \& Conchas, 2009) have clearly indicated that university and community partnerships can make a difference in educational improvement and change. This same body of work acknowledges that in many communities, institutions of higher education are important and powerful untapped assets and these partnerships are hard to sustain.

To encourage partnerships that can bring about real change, university faculty must become more involved in their surrounding communities. One way to support these relationships is to create a faculty reward and evaluation system that takes high-quality community based work into account. The creation of such a system would be "a critical step in moving a campus toward engagement" (Campus Compact, 2010). In addition, Boyer (1997) argued that colleges and universities must change how scholarship is recognized and rewarded. He argued that there must be a focus on using research findings and innovations to remedy societal problems.

This work also clearly aligns with current efforts of the American Association of State College and Universities (AASCU) toward becoming "stewards of place" (AASCU, 2002). The literature on "stewardship of place" suggests that "The publicly engaged institution is fully committed to direct, twoway interaction with communities and other external constituencies through the development, exchange, and application of knowledge, information, and expertise for mutual benefit" (AASCU, 2002, p. 9). The adoption of an engaged scholarship policy would answer this call to action.

Just, equitable, and inclusive education. The literature related to just, equitable, and inclusive education (JEIE) is expansive. Among the most often-cited works from the past 10 years that influenced the work of the Faculty Roles Committee were the writings of Adams, Bell, and Griffin (2007), Banks (2010), Delgado and Stefancic (2012), Spring (2011), and Yosso (2006). These works collectively align well with the prior emphasis of community partnership as they define social justice work in terms of action and collaboration. Notably, Bell (2013) has argued, "The goal of social justice education is full and equal participation of all groups in a society that is mutually shaped to meet their needs" (Bell, 2013, p. 21). This directly speaks to ideals and principles of partnership and collaboration.

Continuing to speak to social justice education, Bell (2013) also stated "Social justice includes a vision of 
society that is equitable and all members are physically and psychologically safe and secure" (p. 21). In the context of higher education, this includes faculty of color feeling safe and secure in their work, specifically review processes for tenure and promotion. However, faculty of color have often asserted that their scholarly and creative endeavors are not fully valued by peers who have secured tenure and advancement based on work that is established using dominant norms (Smith, 2009). To this point, Scheurich and Young (2002) have argued that the "current range of research epistemologies - positivism to postmodernism - arises from the social history and culture of the dominant race ... [and] reinforce that social history" (p. 231). Later, they noted, "epistemologies and research that arise from other social histories ... are not typically considered legitimate within the mainstream research community" (p. 232). This is especially relevant since the epistemological foundation for the research of many Asian Americans, African Americans, Latinos, and Native Americans assumes greater levels of connection to family and community than is the case for dominant epistemological paradigms (Collins, 2000; Hofer, 2010; Krupat, 1993; Yosso, 2006). Thus, engaged scholarship may also serve to open doors for greater creativity and inclusivity within the realm of that which is defined as scholarly activity for the purposes of tenure and promotion.

Defining engaged scholarship. As previously noted, disconnect currently exists between "pursuing community-based scholarship.... and institutional tenure policies" (Ellison \& Eatman, 2008, p. 5). Further, engaged scholarship practices are consistent with those that have been identified as contributing to the recruitment and retention of faculty of color and women in underrepresented fields (Ellison \& Eatman, 2008; Smith, 2009). After reviewing additional literature addressing engaged scholarship, we identified common themes of engaged scholarship leading to a commitment to "public good" (Campus Compact, 2010, p. 5) and encouraging partnerships that bring about real community change. Drawing on these themes, the Faculty Roles Committee examined numerous definitions and was prepared to generate its own. However, the Committee ultimately settled on the following, which the New England Resource Center for Higher Education (n.d.) published to its website. The Committee agreed that this definition addressed each of the previously noted areas of importance:

Engaged scholarship is defined by the collaboration between academics and individuals outside the academy - knowledgeable professionals and the lay public (local, regional/state, national, global) - for the mutually beneficial exchange of knowledge and resources in a context of partnership and reciprocity. The scholarship of engagement includes explicitly democratic dimensions which encourage the participation of non-academics in ways that enhance and broaden engagement and deliberation about major social issues inside and outside the university. It seeks to facilitate a more active and engaged democracy by bringing affected publics into problem-solving work in ways that advance the public good with and not merely for the public.

\section{Step Two: Gather Practice-Oriented Information}

Shortly after initiating the process of reviewing scholarly literature, the Faculty Roles Committee began a process of reviewing tenure and review policies of other institutions and exploring the perceptions of faculty within the College of Education at CSUF. After securing support from the Dean of the College of Education, the Committee contracted Eduventures to interview College of Education deans across the country and review tenure and promotion policies at other institutions that may serve as a model for CSUF. The Committee took upon itself to collect policies from other institutions from the California State University System as well as from other regional colleges and universities. Though Eduventures identified some interest from their interviews with deans, they also uncovered concern that long-standing practices and attitudes in academia would make it difficult to recognize engaged scholarship within tenure and promotion practices. This concern was also present within the literature (Henderson \& Buchanan, 2007). In the end, the Committee was not able to identify any strong models of recognizing engaged scholarship that had been adopted at other colleges or universities. 
Whereas the review of best practices was somewhat disappointing, most of the data gathered from College of Education faculty at CSUF was promising. The Faculty Roles Committee conducted informal focus group interviews with the majority of College of Education faculty members during a retreat in January, 2012. Most professors at the ranks of assistant, associate, and full were interviewed separately, though one focus group consisted of a mixed group that cut across all ranks. The feedback was generally positive, especially from assistant and associate professors. Among the emergent themes, faculty were excited about (a) the potential impact on schools, (b) increased efficiency in getting results into the hands of practitioners and educational leaders, (c) greater inclusivity of research paradigms, especially for faculty of color, (d) the alignment with the research-to-practice orientation of the College's Doctor of Educational Leadership program, and (e) the fit of engaged scholarship with the mission of the College of Education. Faculty concerns centered primarily on the issues of ensuring quality, addressing peer review, and obtaining wide dissemination of findings. After being asked about their perceptions regarding the engaged scholarship project, faculty were invited to brainstorm potential means for implementation. From the portion of the focus groups emerged the idea of replacing one traditional scholarly article with an engaged scholarship project, an idea that would later prove to be critical in obtaining College-wide consensus. After the focus groups were completed, faculty were invited to continue to provide feedback through a College-wide open form, department meetings, and a College-wide survey.

\section{Step Three: Create the Policy Language}

Though faculty had shared concerns about peer-review and dissemination during focus groups and in department meetings, these concerns did not appear to be "deal breakers," so to speak. Members of the Faculty Roles Committee had rather adeptly challenged the objectivity of both concepts. Though generally supportive of the peer review process, many faculty in the College had experienced situations in which reviews had been highly subjective or biased, or situations where the review process was not fully blind. Further, in terms of dissemination, several faculty noted how some of their most influential and frequently cited works were not peer-reviewed. Thus in the end, few faculty seemed highly concerned about broadening the concept of scholarship by expanding the notion of dissemination or reconsidering who counts as "peer" in the peer review process. That said, faculty concerns regarding ensuring quality and rigor were more complex.

The compromise. In light of data from focus groups, surveys, and departmental meetings, it was apparent that the faculty in some departments were more ready to push the bounds of engaged scholarship while others were more reticent regarding the concept. After consulting with several senior-level administrators, it also became clear that significant divisions within the College of Education could compromise the entire project once it moved forward for University-level approval. In that context, the Faculty Roles Committee determined to pursue common language for the entire College of Education, which the various departments could then adopt and cite in their personnel standards. The common language would also serve as stronger statement to the University regarding the importance of engaged scholarship.

With an eye toward the eventual goal of College-wide support for a singular policy statement, members of the Faculty Roles Committee began to consult with faculty members who had shared significant reservations during the focus groups. As noted previously, the issue of quality and rigor emerged as the primary concern. Senior faculty members in particular were concerned about potential perceptions of the College lowering its standards or of faculty securing tenure without first demonstrating core-level skills necessary to maintain a research agenda.

This is where a compromise emerged. As context, each of the five departments in the College rated teaching, scholarship, and service as "inadequate," "progressing," "good" or "excellent" during the tenure and promotion process (some departments additionally included a rating of marginal, adequate and 
inadequate). To secure tenure or advancement, faculty were generally required to be "excellent" in teaching and "excellent" in either scholarship or service with the third area minimally "Good." Faculty who wished to secure early tenure or advancement in rank had to secure "excellent" ratings in all three areas. As a compromise, it was agreed that all faculty members must secure the minimum requirements for "good/progressing" ratings using traditional peer-reviewed works. After faculty members have met the minimum threshold, they could then use an item (or multiple items) of engaged scholarship to earn a rating of "excellent." Although several members of the Faculty Roles Committee were concerned that this compromise could perpetuate the perception that engaged scholarship is less valuable or rigorous than traditional scholarship, the compromise also presented a means to secure support from the vast majority of College of Education faculty as well as from each of the five departments.

Policy language. Once the Committee had negotiated the compromise with several key faculty members, finalizing policy language became a relatively straight-forward process. The Faculty Roles Committee prepared a document that began with the New England Resource Center for Higher Education definition of engaged scholarship followed by the following policy statement (for clarity, all policy language is presented in italics):

A meaningful, high quality, Engaged Scholarship project, as defined per the criteria that follow, may be substituted for one high quality peer-reviewed publication for the purpose of meeting department standards for a rating of excellent in scholarly and creative activities. Engaged scholarship cannot be used to achieve a rating of good or lower.

To further address concerns regarding quality, the following five criteria were established and included with the policy statement:

1. A clear rationale of the need for the work addressed and for the strategies and/or tools with which the work is carried out (The plan must be supported by evidence-based practices).

2. Work should have a conceptual or theoretical basis; i.e., is conducted within the context of existing peer-reviewed knowledge. Normally, this is accomplished through a review of related work in an area showing what has been done in the past and providing a rationale as to why additional work is needed in this area.

3. Multiple forms of evidence shall be provided by the faculty member that demonstrate both the quantitative and qualitative impact of the project. A clear impact on a district or community partner is required. These could include letter from partners, data collected, etc.

4. A description of the evaluation process and outcomes that includes: research questions informed by and situated within the literature; an analysis of findings that are contextualized within the particular community, district, school, or classroom needs and the discipline; implications that illustrate the practical ways in which the project shaped or is shaping lived realities for the better; directions for future work. Evaluation results and implemented changes based on this evaluation must be completed and disseminated before the faculty member can submit this work for the RTP process.

5. Evidence of dissemination activities and feedback from stakeholders must be included. Dissemination may be accomplished in various ways, including formal presentations to partnership groups and reports for partners.

In the absence of formal peer-review, the Faculty Roles Committee recognized that departments would need guidance in terms of evaluating the quality of engaged scholarship items. The following language was included in the policy document to address this concern:

The faculty member must make a case for why this work should be accepted as engaged scholarship. Engaged scholarship and traditional scholarship include a theoretical basis for the work. The quality of traditional scholarship, as determined by the retention, tenure, and 
promotion process, is typically evaluated by peer review journal dissemination. The quality of engaged scholarship is evaluated by the impact on community partners. Department Personnel Committees will review submitted evidence to determine whether a given project is compelling and consistent with the definition of engaged scholarship. Faculty are encouraged to submit multiple forms of evidence, and assure any letters of validation refer concretely to practices of engaged scholarship and reflect the criteria and standards of engaged scholarship as outlined in this document.

Lastly, because of the newness of engaged scholarship and the potential impact on junior faculty, the following statement was added near the end of the policy document:

Pursuing an engaged scholarship project is something that may be undertaken by junior faculty members. However, faculty should be advised that they will need to establish themselves as researchers primarily through the publication of peer reviewed articles/books. While an Engaged Scholarship project adds strength to a faculty member's scholarly record, it does not replace the requirement for scholarly publications.

Step Four: Generate Consensus

After drafting the policy document, it was imperative for the Faculty Roles Committee to achieve consensus across the College that would lead to formal adoption by each department of the engaged scholarship policy. Though noteworthy attention had been paid to communication regarding engaged scholarship throughout the process, quite a few faculty had retired and several others had been newly hired since the launch of the effort. Further, there had been turnover among several department chairs. Thus, in addition to the policy statement, the Committee generated the following table to help clarify the role of engaged scholarship as related to traditional scholarship and service.

Table 1

Comparison of Engaged Scholarship, Traditional Scholarship, and Service

\begin{tabular}{|c|c|c|}
\hline Engaged Scholarship & Traditional Scholarship & Service \\
\hline $\begin{array}{l}\text { - Co-Constructed Inquiry (with } \\
\text { community partners) }\end{array}$ & $\begin{array}{l}\text { - Individually or co- } \\
\text { constructed }\end{array}$ & $\begin{array}{l}\text { - No or limited inquiry or } \\
\text { faculty initiated inquiry }\end{array}$ \\
\hline $\begin{array}{l}\text { - Theoretical basis for } \\
\text { decision-making }\end{array}$ & $\begin{array}{l}\text { - Theoretical basis for } \\
\text { decision-making }\end{array}$ & $\begin{array}{l}\text { - No or limited theoretical } \\
\text { basis for decision-making }\end{array}$ \\
\hline $\begin{array}{l}\text { Systematic plan for } \\
\text { evaluation that includes } \\
\text { evidence of continued } \\
\text { improvement/change based } \\
\text { on evaluation. }\end{array}$ & - Analysis of findings & $\begin{array}{l}\text { - No evaluation or one time } \\
\text { evaluation }\end{array}$ \\
\hline $\begin{array}{l}\text { - Multiple and broad public } \\
\text { Dissemination }\end{array}$ & $\begin{array}{l}\text { - Publication or scholarly } \\
\text { presentation }\end{array}$ & $\begin{array}{l}\text { - No Dissemination/limited } \\
\text { dissemination }\end{array}$ \\
\hline $\begin{array}{l}\text { - Verifiable community } \\
\text { impact, resulting in an } \\
\text { intellectual and imaginative } \\
\text { work that yields a "public } \\
\text { good" product (Ellison \& } \\
\text { Eatman, 2008) }\end{array}$ & $\begin{array}{l}\text { - Possible or no indicated } \\
\text { community impact }\end{array}$ & $\begin{array}{l}\text { - Possible or no indicated } \\
\text { community impact }\end{array}$ \\
\hline
\end{tabular}


In spring 2014, all five departments voted overwhelmingly to adopt the engaged scholarship policy language. However, this adoption was pending final University-level approval of the policy.

\section{Step Five: Obtain Final Approval}

In fall 2014, the engaged scholarship language was added to each of the department's personnel standards. These five documents, along with the engaged scholarship policy, were submitted to the University's Faculty Personnel Committee (FPC), which oversees department standards. In November, the FPC identified three areas of concern. The first concern was somewhat technical in terms of refining the language in the personnel standards of the five departments to better align with University policy.

The second issue involved dissemination of the work. Specifically, the FPC argued that dissemination needed to be broader than simply reporting findings to the partner school or institution. Thus, the fifth criterion for evidence of quality for engaged scholarship was revised to read as follows: "Evidence of dissemination activities and feedback from stakeholders must be included. Dissemination must include a broad audience."

Lastly, the FPC indicated that they were not comfortable with the idea that an engaged scholarship project could also lead to a peer-reviewed publication. The committee indicated that this policy would allow for a single project to ultimately be counted twice. In response, the Faculty Roles Committee noted that faculty members may count certain types of funded grants as publications, and those faculty may also publish peer-reviewed journal articles from the grant. In such situations, the faculty is allowed to count both the grant and the journal article as publications. The Faculty Roles Committee suggested that the University should allow for the same standard for engaged scholarship. This argument was acknowledged and supported by the Provost.

Once these changes were addressed, the changes and the documents were forwarded to the Provost. The Provost made suggested changes which were discussed above. The College of Education's documents were approved by the University in June of 2015 to begin fall 2016.

\section{Discussion}

In hindsight, the five steps of the process used to incorporate engaged scholarship within institutional policies align well with many models for leading change generally (Kotter, 2012; Martin, 2002; Trice \& Beyer, 1993) as well as those written specifically for higher education (Kezar, 2013; Tierney, 1999). Though an in-depth analysis of the change process extends beyond the purpose of this paper, the attention of the Faculty Roles Committee to organizational culture, communication, compromise, building consensus and a shared vision, and socialization were all keys to the success of the initiative.

For this particular process, careful attention to grounding the concept of engaged scholarship within scholarly literature was critical. Trice and Beyer (1993) noted that changes that affect organizational culture "involve a break with the past; cultural continuity is noticeably disrupted" (p. 395). When applying this idea to higher education, Tierney (1999) noted, "The leader needs to be able to develop the sense that changing structures do not destroy core beliefs. Structures change; core ideologies undergo contextual interpretation but remain in place unless found false" (p. 52). Several faculty membersnotably full professors with long histories at CSUF - expressed concern for watering down scholarship and lowering standards. By grounding the concept of engaged scholarship within scholarly works which addressed engaged scholarship as well as the associated concepts of partnership and just, equitable, and inclusive education, the Committee assuaged many of these concerns. Further, a large number of faculty across all ranks were drawn to the idea of engaged scholarship because of how it aligned with the mission 
of the College and the University. Thus, engaged scholarship was a reinterpretation of a core ideology-a refocusing of scholarship on the University's core mission.

Communication was also a critical component of the change process. Whereas the Committee allocated specific attention to how it would deliver messages regarding engaged scholarship, the listening component of the communication process was most critical. Though we would not describe this process as a full "cultural study," Martin's (2002) conception of the role of listening fits well with the Committee's process:

Cultural study ... [involves] a willingness to look beneath the surface, to gain an in-depth understanding of how people interpret the meanings of ... manifestations and how these interpretations from patterns of clarity, inconsistency, and ambiguity that can be used to characterize understandings of working lives (pp. 4-5).

The point is, that for as hallowed a concept scholarship is and considering the central role it plays to the work of faculty, it is also a concept that is often not well-defined or understood by the very faculty who so revere it. This became increasingly clear as faculty almost simultaneously promoted the value of peerreview while challenging its objectivity.

This type of listening also opened the door for the policy compromise that proved central to building broad consensus within the College for the inclusion of engaged scholarship. On the one hand, if a highquality engaged scholarship item carries the same rigor and value as a traditional work of scholarship, why should it not count toward a rating of "progressing"- the minimum level standard for scholarly productivity among probationary faculty? On the other hand, if engaged scholarship is not as rigorous or valuable as traditional scholarship, why should it carry the same weight as traditional scholarship in moving a faculty member from a rating of "progressing" to "excellent" in scholarship? Tierney (1999) used the metaphor of a "tango" when describing leadership, noting that it is a "comparative, reciprocal process" (p. 50). The members of the Faculty Roles Committee felt strongly that a high-quality item of engaged scholarship should carry the same weight as a high-quality item of traditional scholarship within the tenure and review process. That said, the committee was also willing to allow space for a reciprocal process that would lead to adoption of the policy, even if it involved a somewhat ambiguous understanding of the ideals of scholarship and engaged scholarship.

While the compromise strategy was successful in building consensus that led to approval of the engaged scholarship policy, a word of caution is in order. Scholars such as Scheurich and Young (2002) and Smith (2009) have noted that privileging traditional scholarship inherently communicates messages of the "value" for traditional, Western epistemologies over and against the worldviews of many people of color; among others. This process reinforces structures that marginalize and oppress faculty of color in academe. We have presented engaged scholarship, with its connections to community and practice, as a still limited, though potentially more inclusive scholarly umbrella. To the degree that this is true, the compromise enacted to pass the engaged scholarship policy leaves in place elements of an oppressive structure. If engaged scholarship is not fully equal to traditional scholarship, then neither are some of the cultural and epistemological worldviews included under this umbrella.

This concern is among the next steps that will need to be addressed as the new engaged scholarship policy is put into practice. In fact, knowing that there is still some professional development that needs to occur on this process, the College has decided to spend the spring 2016 semester educating all faculty and in particular, department personnel committees, on the newly included criteria of engaged scholarship. Some considerations as the College moves forward with this new process in fall of 2016 include; addressing guidelines for both reviewers and submitters, delineating what will be accepted as documentation of 
impact on area schools and communities, and the need to generate a "database" of engaged scholarship projects that would be accepted.

Overall, the College of Education at CSUF is hopeful that this move to include engaged scholarship as part of the tenure and promotion process will lead to better alignment of the University mission. In addition, by implementing this change faculty will be allowed to use research findings and innovations to remedy societal problems (Boyer, 1997). Finally, by embracing the idea of "stewards of place" (AASCU, 2002) the college can better address issues of just, equitable, and inclusive education by making a stronger impact in the community and forming true two-way partnerships with our constituencies. 


\section{References}

Adams, M., Bell, L. A., \& Griffin, P. (Eds.). (2007). Teaching for diversity and social justice (2nd ed.). New York, NY: Routledge.

American Association of State Colleges and Universities (2002). Stepping forward as stewards of place. New York: American Association of State Colleges and Universities.

Banks, J. A. (2010). Multicultural education: Issues and perspectives (7th ed.). Hoboken, NJ: Wiley \& Sons.

Bell, L. A. (2013). Theoretical foundations. In M. Adams, W. Blumenfeld, C. Castaneda, H. W.

Hackman, M. L. Peters, \& X. Zuniga (Eds.), Readings for diversity and social justice (3rd ed.; pp. 21-25).

New York, NY: Routledge.

Boyer, E. (1996). The scholarship of engagement. Journal of Public Outreach 1 (1), 11-20. doi:

http://dx.doi.org/10.2307/3824459

Boyer, E. L. (1997). Scholarship reconsidered: Priorities of the professoriate. San Francisco: Jossey-Bass.

California Dropout Research Project (2015). California school district graduation rates: 2009-10 thru 2013-14. Retrieved from

https://public.tableau.com/profile/california.dropout.research.project\#!/vizhome/CaliforniaGraduationRat es/Dashboard1.

California Dropout Research Project (2011). City profile. Retrieved October 20, 2011 from http://cdrp.ucsb.edu/pubs_cityprofiles.htm.

Campbell, C., \& Levin, B. (2009). Using data to support educational improvement. Educational Assessment, Evaluation, and Accountability 21 (1), 47-65. doi: http://dx.doi.org/10.1007/s11092-0089063-X

Carnoy, M., \& Levine, H.M. (1985). Schooling and work in the democratic state. Palo Alto: Stanford University Press.

Campus Compact (n.d.). Campus compact: Education citizen. Building communities. Retrieved from http://www.compact.org/.

Collins, P. H. (2000). Black feminist thought. New York, NY: Routledge.

Delgado, R., \& Stefancic, J. (2012). Critical race theory: An introduction (2nd ed.). New York, NY: University Press.

Ellison, J., \& T. K. Eatman. (2008). Scholarship in public: Knowledge creation and tenure policy in the engaged university. Syracuse, NY: Imagining America.

Green, R. G. (2008). Tenure and promotion decisions: The relative importance of teaching, scholarship, and service. Journal of Social Work Education 44 (2), 117-127. doi:

http://dx.doi.org/10.5175/JSWE.2008.200700003 
Henderson, B. B., \& Buchanan, H. E. (2007). The scholarship of teaching and learning: A special niche for faculty at comprehensive universities? Research in Higher Education 48 (5), 523-543. doi: http://dx.doi.org/10.1007/s11162-006-9035-2

Hofer, B. K. (2010). Personal epistemology in Asia: Burgeoning research and future directions. The AsiaPacific Education Researcher 19 (1), 179-184. doi: http://dx.doi.org/10.3860/taper.v19i1.1516

Jaschik, S. (2007). Scholarship reconsidered' as tenure policy. Inside Higher Education. Retrieved from http://www.insidehighered.com/news/2007/10/02/wcu.

Kezar, A. J. (2013). How colleges change: Understanding, leading, and enacting change. New York, NY: Routledge.

Kotter, J. P. (2012). Leading change. Cambridge, MA: Harvard Business Review Press.

Krupat, A. (1993). New voices in Native American literary criticism. Washington, DC: Smithsonian Institution Press.

Leonard, J. (2011). Using Bronfenbrenner's ecological theory to understand community partnerships: A historical case study of one urban high school. Urban Education 46 (5), 987-1010. doi: http://dx.doi.org/10.1177/0042085911400337

Martin, J. (2002). Organizational culture: Mapping the terrain. Thousand Oaks, CA: Sage. doi: http://dx.doi.org/10.4135/9781483328478

Moss, P. A. (Ed.). (2007). Yearbook: Evidence and decision-making 106 (1). National Society for the Study of Education. Teachers College, Columbia University, New York, NY.

Mandinach, E. B. (2012). A perfect time for data use: Using data-driven decision making to inform practice. Educational Psychologist 47 (2), 71-85. doi: http://dx.doi.org/10.1080/00461520.2012.667064

Maurrasse, D. J. (2001). Beyond the campus: How colleges and universities form partnerships with their communities. London: Routledge.

New England Resource Center for Higher Education (n.d.). Engaged scholarship. Retrieved from http://www.nerche.org/index.php?option=com_content\&view=article\&id=265\&cati=28.

Noguera, P. A. (1998 July 9). Toward the development of school and university partnerships based upon mutual benefit and respect. In Motion Magazine. Retrieved from

http://www.inmotionmagazine.com/pnsup1.html.

Person, D.R., Garcia, Y., Fujimoto, E., Nguyen, K., Saunders, K., \& Hoffman, J.L. (2014). Increasing educational attainment and aspiration in an underserved community. The Urban Review 46 (3), 493-506. doi: http://dx.doi.org/10.1007/s11256-014-0282-9

Rodríguez, L. F., \& Conchas, G. Q. (2009). Preventing truancy and dropout among urban middle school youth understanding community-based action from the student's perspective. Education and Urban Society 41 (2), 216-247. doi: http://dx.doi.org/10.1177/0013124508325681 
Scheurich, J. J., \& Young, M. D. (2002). White racism among white faculty: From critical understanding to antiracist activism. In W. A. Smith, P. G. Altbach, \& K. Lomotey (Eds.), The racial crisis in American higher education (Rev. ed.) (pp. 221-242). New York, NY: State University of New York Press.

Smith, D. G. (2009). Diversity's promise for higher education: Making it work. Baltimore, MD: The Johns Hopkins University Press.

Spring, J. (2011). The American school: A global context from the puritans to the Obama era (8th ed.). New York, NY: McGraw Hill.

Tierney, W. G. (1999). Building the responsive campus: Creating high performance colleges and universities. Thousand Oaks, CA: Sage.

Trice, H. M., \& Beyer, J. M. (1993). The cultures of work organizations. New York, NY: Prentice Hall.

Yosso, T.J. (2006). Critical race counterstories along the Chicana/Chicano educational

Pipeline. New York, NY: Routledge.

\section{Author Information}

Lisa Kirtman, Ph.D. is a Professor and the Associate Dean for the College of Education at California State University, Fullerton (CSUF). She joined the faculty in 2000 after completing her Ph.D. at UC Berkeley. During this time she has served on numerous committees and worked as the Chair of the Department of Elementary and Bilingual Education for 5 years. She has also published fourteen articles in peer-reviewed journals and has presented her work at various local, regional, and national conferences. Dr. Kirtman was an elementary and a middle school teacher prior to her work at CSUF. Her research interests include faculty development and support as well as mathematics education.

Lisa Kirtman, Ph.D.

Associate Dean

College of Education

California State University, Fullerton

2600 Nutwood Ave, Suite 500

Fullerton, CA 92831

(657) 278-5901

Email: 1kirtman@exchange.fullerton.edu

Erica Bowers, Ed.D., is an Associate Professor and Chair of the Department of Literacy and Reading Education in the College of Education. For the past seven years she has also served as the Director of the CSUF Hazel Miller Croy (HMC) Reading Center which serves striving readers from the local community. Her research agenda includes struggling readers and assessment practices, academic language, and English language learners. She joined the faculty at CSUF in the fall of 2006 after completing her Ed.D. in Literacy and Language at the University of Southern California. She serves on the board of the California Reading Association as the state liaison to the International Literacy Association. For the coming academic year, 2015-16, Dr. Bowers will serve as the chair of the Planning, Resource, and Budget Committee (PRBC). Prior to her work at CSUF, Dr. Bowers was an elementary school teacher, district trainer and Reading Specialist for more than 15 years.

Pr. Erica Bowers, Ed.D.,

Associate Professor 
Department of Literacy \& Reading Education

College of Education

California State University, Fullerton

2600 Nutwood Avenue, Suite 570

Fullerton, CA 92831

(657) 278-3497

ebowers@fullerton.edu

John L. Hoffman, Ph.D., is an associate professor of educational leadership at California State University, Fullerton where he also serves as the director of the doctor of educational leadership program and the chair of the Department of Educational Leadership. Before transitioning to faculty, John spent 10 years working in administrative roles in academic and student affairs, seven of which were as a dean of students. He has experience in the development of theory-informed programs that enhance the success and retention of students of color; early interventions addressing student wellness and achievement; and the assessment of student learning in the co-curriculum. John has received professional awards from Western Association for College and University Housing Officers (WACUHO) for his diversity and leadership work as a dean of students and from the National Association of Student Personnel Administrators (NASPA) for his professional mentoring efforts. His research interests focus on assessment and accountability, professional competencies in student affairs and higher educational leadership, and professional development and mentoring. John earned his Ph.D. in Higher Education Policy and Administration from the University of Minnesota.

John L. Hoffman, Ph.D.

Director

Doctor of Educational Leadership Program

Chair

Department of Educational Leadership

California State University, Fullerton

2600 Nutwood Avenue, Suite 520

Fullerton, CA 92831

(657) 278-4023

jhoffman@fullerton.edu 